\title{
Impulsivity and Alcohol Involvement: Multiple, Distinct Constructs and Processes
}

\author{
Andrew K. Littlefield • Angela K. Stevens • \\ Kenneth J. Sher
}

Published online: 20 December 2013

(C) Springer International Publishing AG 2013

\begin{abstract}
Of all the personality traits associated with problematic alcohol involvement, traits related to impulsivity appear to show the most robust relations to alcohol use and alcohol-related problems. This article reviews both seminal articles that focus on broadband measures of impulsivity and newer research linking more specific impulsivity-related traits to the development and course of problematic alcohol involvement, with a specific focus on self-report measures of impulsivity-related traits. Specifically, empirical support for different theoretical models that account for the overlap between impulsivity-related traits and problematic alcohol involvement is discussed, including current limitations of existing research. Recent studies suggest that specific impulsivity constructs relate to distinct aspects of alcohol-related behavior. Further, there is emerging evidence that problematic alcohol use and impulsivity-related traits are dynamically related, such that changes in these constructs appear to correlate during specific developmental periods. We close by discussing potential research directions that may provide increased clarity in understanding the impulsivity-alcohol relation.
\end{abstract}

Keywords Alcohol use disorders - Alcohol involvement . Personality $\cdot$ Impulsivity $\cdot$ Urgency $\cdot$ Behavioral undercontrol · UPPS-P

\footnotetext{
A. K. Littlefield $(\triangle) \cdot$ A. K. Stevens

Department of Psychology, Texas Tech University, Psychology

Building, Box 42051, Lubbock, TX 79409, USA

e-mail: andrew.littlefield@ttu.edu

A. K. Stevens

e-mail: angela.stevens@ttu.edu

\section{K. J. Sher}

Department of Psychological Sciences, University of Missouri, 211

South 7th St, Psychology Building, Columbia, MI 65211, USA

e-mail: sherk@missouri.edu
}

\section{Introduction}

Historically, alcohol use and misuse has been associated with traits broadly linked to self-control. Specifically, personality factors such as impulsivity/disinhibition have been robustly linked to problematic alcohol involvement. Although there are numerous approaches to defining and assessing the constructs of "impulsivity" and "self-control" $[1,2]$, recent research has increasingly focused on linking more narrowband measures of impulsivity-like traits to distinct features of alcohol involvement, such as drink quantity/frequency and alcohol-related problems [3]. The importance of designing assessments to capture more homogeneous constructs is being increasingly recognized [4]. Smith et al. [4, p. 272] argue that the use of more homogeneous dimensions provides "validity, utility, and parsimony," whereas the use of broader, composite measures "can retard scientific progress and hamper clinicians' efforts to understand and treat dysfunction." Perhaps the clearest example of designing more homogeneous measures of impulsivity is the work of Whiteside and Lynam [5] which identified four distinct personality facets related to impulsive-like behavior: sensation seeking, lack of planning, lack of perseverance, and urgency (acting rashly when distressed). Further work indicated that urgency can be associated with both positive affect and negative affect/distress [3]. As reviewed in detail later, there is evidence that these five specific impulsivity measures show differential relations to several alcoholrelated behaviors in various domains (e.g., drinking frequency vs alcohol-related problems; see [6], Table 1).

The purpose of this article is to review recent findings that link traits associated with impulsivity and self-control to problematic alcohol use. Expanding on similar reviews focusing on the link between specific personality characteristics and alcohol involvement [7-9], this review incorporates the most recent findings pertaining to the relation between impulsivityrelated traits and problematic alcohol involvement. More specifically, a subset of previously reviewed theoretical models focusing on the relation between impulsivity and problematic 
Table 1 Overview of relation between impulsivity facets based on the UPPS-P formulation and various alcohol-related outcomes

\begin{tabular}{|c|c|c|}
\hline Trait & Description/example & Link to alcohol-related outcome \\
\hline Sensation seeking & $\begin{array}{l}\text { The tendency to seek out new and thrilling experiences. } \\
\text { "I generally seek new and exciting experiences } \\
\text { and sensations" }\end{array}$ & $\begin{array}{l}\text { Increased drinking frequency, increased binge drinking, } \\
\text { changes over time are linked to changes in alcohol use, } \\
\text { associated with alcohol enhancement motives }\end{array}$ \\
\hline Lack of planning & $\begin{array}{l}\text { The tendency to act without thinking. } \\
\text { Reverse-scored "I usually think carefully } \\
\text { before doing anything" }\end{array}$ & $\begin{array}{l}\text { Increased drinking frequency, alcohol dependence, may be } \\
\text { a genetic correlate of alcohol use disorders, changes may } \\
\text { correlate with changes in drinking, alcohol-related problems, } \\
\text { relationship with dependence is stronger when individuals } \\
\text { are high in enhancement motives }\end{array}$ \\
\hline Lack of perseverance & $\begin{array}{l}\text { The inability to remain focused on a task. } \\
\text { "I tend to give up easily" }\end{array}$ & $\begin{array}{l}\text { Increased drinking quantity, increased drinking frequency, may } \\
\text { be predictive of drinking onset }\end{array}$ \\
\hline Positive urgency & $\begin{array}{l}\text { The tendency to act rashly when experiencing } \\
\text { extremely positive emotion. } \\
\text { "When I am in a great mood, I tend to get into } \\
\text { situations that could cause me problems" }\end{array}$ & $\begin{array}{l}\text { Increased drinking frequency, relates to development of } \\
\text { alcohol-related problems }\end{array}$ \\
\hline Negative urgency & $\begin{array}{l}\text { The tendency to act rashly in response to distress. } \\
\text { "When I feel bad, I will often do things I later } \\
\text { regret in order to make myself feel better now" }\end{array}$ & $\begin{array}{l}\text { Increased drinking frequency, relates to development of } \\
\text { alcohol-related problems, alcohol dependence, relationship } \\
\text { with dependence is stronger when individuals are high } \\
\text { in coping motives }\end{array}$ \\
\hline
\end{tabular}

This summary of the link between various impulsivity-related traits and alcohol-related outcomes refers both to findings using the UPPS-P impulsivity scales and to findings using measures that predate the scales but assess similar content [6]. Impulsivity facet descriptions taken were from Cyders and Smith [64]. Although the traits listed here correlate bivariately with many different alcohol outcomes, we have summarized what are considered to be the strongest relations between these traits and specific alcohol outcomes

alcohol involvement [9] will be introduced. Within each of these models, seminal articles linking problematic alcohol involvement to broadband measures of impulsivity will be briefly reviewed before we turn our attention to more recent articles that focus on more distinct impulsivity facets. Implications and future work to further delineate more fine-grained relations between impulsivity-like traits and alcohol outcomes will also be discussed.

Given space constraints, there are several important areas that are not discussed within the scope of this review. This review largely focuses on self-report measures of impulsivity traits rather than laboratory-based, behavioral approaches [10, 11]. Whereas traits related to impulsivity start to develop early in life, our review focuses primarily on the alcohol-impulsivity link during emerging and young adulthood, a timeframe that also encompasses the peak prevalence of alcohol use and alcohol use disorders (AUDs). Although the strength of any relation between impulsivity and alcohol involvement during childhood and adolescence might be dampened by moderators associated with access and opportunity, numerous studies have examined the link between traits related to impulsivity and problematic alcohol use during this timeframe [12•, 13, 14].

\section{Genetic Diathesis}

The concept that genetic diathesis, or risk, for problematic alcohol involvement might be mediated by personality was first proffered by Cloninger [15]. Sher et al. [16] demonstrated that a family history of alcoholism predicted higher levels of a broad trait labeled "behavioral undercontrol" (comprising seven subscales including items from measures of novelty seeking, extraversion, psychoticism, and impulsivity; see [16] for more details), which in turn predicted high levels of alcohol expectancies and alcohol involvement [17]. However, given no genetic controls (e.g., a twin design) were used, the family history influence on behavioral undercontrol and alcohol outcomes could be attributed to both genetic and environmental forces. Slutske et al. [18] were the first to document the genetic correlation between impulsivity-like traits and AUDs using a twin design. They used data from 3,000 twin pairs and showed that genetic variance in the broad construct referred to as behavioral undercontrol accounted for $40 \%$ of the genetic variance in alcohol dependence. Notably, as with the behavioral undercontrol variable used by Sher et al. [16], the behavioral undercontrol measure used by Slutske et al. [18] was quite heterogeneous (i.e., it was created by summing Tridimensional Personality Questionnaire (TPQ) [19] novelty seeking score, Eysenck Personality Questionnaire-Revised (EPQ-R) [20] psychoticism score, and EPQ-R reverse-scored lie scale score) and thus contained items that would not be contemporarily considered by some to reflect impulsivity facets [e.g., "Is (or was) your mother a good woman?" from EPQ-R psychoticism; "Do you practice what you preach?" from the EPQ-R lie scale]. In a more recent study using a more refined measure related to impulsivity, Littlefield et al. [21•] examined the relation between control, a subscale of constraint from the Multidimensional Personality Questionnaire (MPQ) [22], and 
DSM-IV AUD symptoms. This scale contains similar items as the lack of planning scale from the UPPS (e.g., from MPQ control, "I like to have detailed plans before doing something"; from UPPS lack of planning, "I like to stop and think things over before I do them") and can be thought as of reverse-scored measure of impulsivity. The genetic correlation between AUD symptoms and control was -0.50 , suggesting $25 \%$ of the genetic variance in control overlapped with genetic variance in AUD symptoms. This estimate is lower than what was found by Slutske et al. [18], where behavioral undercontrol accounted for $40 \%$ of the genetic variance in alcohol dependence. In addition to different measures of impulsivity-like traits, the difference between the two studies might also be due to the disparate sample characteristics (see [21•] for more details). Despite differences in the magnitude of the association, these studies suggest that covariation in AUDs and specific impulsivity measures (i.e., a broad, heterogeneous measure of behavioral undercontrol and a narrower measure of impulsivity that reflects a lack of planning) is influenced by genetic factors and that these impulsivity constructs represent a heritable diathesis for AUDs. Notably, less is known about the genetic overlap between AUDs and other specific impulsivity facets (e.g., negative urgency).

\section{Developmental Models of the Personality-Substance Relation}

Barnes [23] first noted that personality traits linked to clinical alcoholism differed from traits associated with prealcoholism and identified changes in numerous traits among clinical alcoholics. Consistent with this work, recent studies have empirically linked correlated changes between traits associated with impulsivity and alcohol-related problems. Littlefield et al. [24] used an impulsivity scale composed of items from the short form of the TPQ [25] (e.g., "I often follow my instincts, hunch, or intuition without thinking through all the details") and the Eysenck Personality Inventory [26] (e.g., "I often do things on the spur of the moment") which showed the highest correlation ( $r=0.56)$ with UPPS lack of planning in a separate sample (see [27] for more details). Changes in this impulsivity measure correlated with changes in alcoholrelated problems (see [24] for more details) from roughly 18 to 35 years of age, such that individuals who showed more pronounced decreases in impulsivity also demonstrated sharper declines in alcohol problems. Similarly, Hicks et al. [28] assessed whether different patterns of DSM-III-R AUDs (i.e., no diagnosis, AUD onset, AUD desistance, persistent AUD) across two time points (17 and 24 years of age) would stunt normative declines in behavioral disinhibition (reverse-scored MPQ constraint) observed during this time span. Consistent with the findings of Littlefield et al. [24], individuals in the desistance group showed significantly larger declines in MPQ constraint compared with individuals with persistent AUDs. However, even the AUD-persistent group showed significant declines in MPQ constraint, suggesting that a chronic pattern of AUDs may slow but not prohibit normative decreases in impulsivity-related traits.

Although a comprehensive review is beyond the scope of this article, changes in traits related to impulsivity may also be related to changes in alcohol involvement during adolescence. Using data from the National Longitudinal Survey of Youth, Quinn and Harden [29] demonstrated that changes in impulsivity (assessed using three items, e.g., "I often get into a jam because I do things without thinking"), but not sensation seeking (assessed using three items, e.g., "I enjoy taking risks"), significantly correlated with change in alcohol use from 15 to 26 years of age. Importantly, and in contrast with previous findings from this sample obtained using identical measures across a similar timeframe (ages 12-24 years) but a different modeling strategy [30] (see [31] for more details), this more recent article also suggested a strong and statistically significant correlation ( $r=0.67)$ between changes in sensation seeking and impulsivity. These findings suggest that (a) individual differences in lack of planning impulsivity may relate to individual differences in alcohol use from adolescence to emerging adulthood, (b) in contrast to proposed dual process models [32], change in impulsivity and sensation seeking may strongly track within individuals across time rather than reflect distinct developmental phenomena (at least during certain timeframes or when specific modeling procedures are used), and (c) modeling choice can significantly impact estimates (and therefore substantive conclusions) derived from these models, and thus researchers should consider and contrast findings from alternative modeling strategies [33, 34]. Finally, although sensation seeking did not significantly correlate with changes in alcohol use in the study described above, other research suggests younger adolescents who show greater increases in self-reported sensation seeking across a 3-year span (roughly 14-16 years of age) were more likely to show increases in alcohol use [29]; thus, change in sensation seeking may also relate to increases in alcohol use among adolescents.

Although correlational studies are inherently limited in their ability to provide evidence for causality, more recent research has focused on elucidating the causal relationship between changes in alcohol involvement and change in traits related to impulsivity. Littlefield et al. [35] showed that a trajectory group comprising individuals who exhibited the sharpest decreases in impulsivity (using the same sample and measure of impulsivity as Littlefield et al. [24]) from the age of 18 years to 25 years also showed the most pronounced decreases in several alcohol-related indices (including consumption and consequence measures) across this timeframe. On the basis of the patterns found by Littlefield et al. [35], change in alcohol problems appeared to be a consequence, 
rather than a cause, of impulsivity change (see $[35,36 \bullet$ for more details). Quinn et al. [36•] used latent difference score models [37] and personality items from the ZuckermanKuhlman Personality Questionnaire [38] to show that heavy drinking in the sophomore year of college prospectively predicted change in impulsivity ("I very seldom spend much time on the details of planning ahead") and sensation seeking (e.g., "I like doing things just for the thrill of it") between high school and the senior year of college. Thus, Quinn et al. [36 $\left.6^{\circ}\right]$ proposed that these models offer evidence for a directional transactional relationship between heavy alcohol use and subsequent change in impulsivity and sensation seeking, such that these traits predict changes in alcohol use, which in turn predict changes in these traits.

Importantly, Quinn et al. [36•] also speculated that such transactional models might underlie previous findings, such as those reported by Littlefield et al. [24]. To test this proposition, Littlefield et al. [39•] reanalyzed the dataset from [24] as well as another large, prospective sample of college students [39॰]. There was no evidence that alcohol-related problems or heavy drinking predicted subsequent increases in impulsivity in the dataset from [24]. Further, using another large prospective sample that included an assessment of novelty seeking (from the short TPQ [25]), only more proximal heavy drinking predicted changes in novelty seeking (i.e., sophomore year, but not freshman year, heavy drinking predicted changes in novelty seeking between the freshman and the senior year; see [39•] for details). Notably, across both samples there was consistent evidence of correlated changes between alcohol involvement and these measures of impulsivity [39•].

Perhaps of most importance, structural equation models using correlational, even prospective, data (such as all the studies just reviewed) cannot distinguish between various causal and noncausal models [40] (see [39॰] for more details). Thus, other methods (e.g., incorporating instrumental variables [41], or true experiments) are needed to render firmer conclusions regarding the functional relations between changes in alcohol involvement and impulsivity-like traits. As noted in $\left[39^{\circ}\right.$, p. 782$]$, it should not be axiomatic that impulsivity traits casually relate to alcohol involvement (or vice versa) and "alternative causal and noncausal relations should be entertained."

\section{Impulsivity and Affect-Regulation Motives}

Regulating both positive and negative emotions appears to be one of several reasons individuals use substances. Cooper [42] created and validated a model for drinking motives based on the previous work of Cox and Klinger [43, 44], resulting in four motivational factors: (1) intrinsic, positive reinforcement ("enhancement"), (2) extrinsic, positive reinforcement for social rewards ("social"), (3) intrinsic, negative reinforcement (“coping"), and (4) extrinsic, negative reinforcement to avoid social disapproval ("conformity").

Broadly, personality traits (including impulsivity-like traits) are believed to influence general behavioral motivation. As a corollary, it is expected that personality traits affect specific alcohol-related motivation, such as those related to internal affect regulation. It has also been posited that motives proximally influence substance use and mediate the more distal factors, such as personality [7, 43-48].

Indeed, there are numerous studies suggesting internal drinking motives are a significant statistical mediator of the relation between personality traits and substance use outcomes, including personality traits related to impulsivity (e.g., sensation seeking [45]; see [48, 49] for reviews). Recently, differences in developmental changes in drinking motives have been implicated as an important mechanism in which impulsivity may influence changes in alcohol problems. Littlefield et al. [27] found that change in impulsivity (using the same measure as in [24] that contains lack of planning type items) impacts changes in coping motives, such that individuals who evince a more pronounced decrease in impulsivity also show marked decreases in coping motives, which in turn predict more pronounced decreases in alcohol problems. These results imply that changes in coping motives mediate the relationship between changes in impulsivity and alcohol problems of this type, suggesting these constructs should be viewed within the same development framework.

In addition to tests of whether motives mediate the relation between impulsivity and substance use, some researchers have examined whether motives and distinct impulsivity facets interact to predict alcohol involvement. Using a prospective dataset tracking women across the first year of college, Stojek and Fischer [50] tested whether distinct impulsivity facets, as measured by the UPPS-P [5], interacted with drinking motives to predict alcohol dependence symptoms. As predicted, there was a significant interaction between drinking to cope and negative urgency to predict alcohol dependence symptoms, such that the relation between negative urgency and alcohol dependence symptoms was substantially stronger among individuals high in coping motives to drink compared with individuals low in these motives. These authors also found a significant interaction between enhancement motives and lack of planning, with lack of planning being a stronger predictor of dependence among those high in enhancement motives. Importantly, supplementary analyses removing covariates (e.g., other motive and impulsivity measures) suggested that although the interaction between negative urgency and coping motives remained statistically significant, the interaction between lack of planning and enhancement motives became statistically nonsignificant, indicating potential suppressor effects in the original model. A significant interaction between negative urgency and enhancement motives was also found in these supplementary analyses, 
suggesting that higher levels of negative urgency increase the influence of both positive and negative reinforcement motives on alcohol dependence symptoms when these personality variables are modeled separately.

There are several issues to consider regarding the literature involving impulsivity-like traits, drinking motives, and alcohol involvement [8]. Manifest measures of personality and drinking motives tend to show small to medium correlations $[46,49]$, which suggests that these traits account for only a small proportion of variance in drinking motives. Although some have claimed rather specific personality-motive relations [48], there is also a lack of specificity concerning the relationship between drinking motives and distinct personality traits to some extent, such that traits related to impulsivity (which have traditionally been linked to enhancement motives) may also relate to coping motives [27, 51]. Further, studies using intensive-repeated measures (such as dailydiary studies) have generally not found empirical support that global drinking motives moderate within-person mooddrinking relations $[52,53]$, although very recent evidence from ecological momentary assessment data showed that endorsing enhancement motives was uniquely associated with finding drinks to be pleasurable, whereas endorsing coping motives was associated with finding drinks to alleviate negative symptoms [54]. Finally, although it is beyond the scope of this review, traits broadly related to impulsivity have also been indicators of "pharmacological vulnerability" to alcohol (e.g., traits may moderate the extent to which alcohol dampens stress or impacts affect $[7,8])$.

\section{Specific Impulsivity-Related Traits Are Linked to Specific Alcohol Domains}

Perhaps one of the most interesting developments emerging from more recent studies that use more refined and specific measures of impulsivity and alcohol involvement is that specific impulsivity-related traits appear to relate to distinct alcohol domains. A recent meta-analysis [6] demonstrated that lack of perseverance was the strongest predictor of drinking quantity, positive and negative urgency most strongly predicted drinking problems, negative urgency and lack of planning were the strongest predictors of alcohol dependence, and all traits equally predicted drinking frequency (see Table 1). These findings suggest that "lumping" approaches involving impulsivity and alcohol involvement (e.g., studies that create composites of several impulsivity facets or combine alcohol consumption with alcohol problems) may mask potential finegrained relations among these constructs. Further, these findings indicate that specific impulsivity constructs may be more or less relevant to various stages involved in the development of AUDs (e.g., lack of perseverance may be especially predictive of drinking onset, whereas urgency measures may more strongly relate to the development of alcohol-related problems).

\section{Clinical Implications}

Given that traits related to impulsivity appear to both directly and indirectly contribute to the development and course of problematic alcohol involvement, incorporating measures of impulsivity within AUD treatment protocols may prove beneficial. For example, on the basis of the observation that changes in impulsivity measures (which reflect lack of planning) correlate with reductions in several indices of alcohol involvement, Littlefield et al. [24] suggested that tracking changes in impulsivity across treatment might be helpful in determining relapse susceptibility (which may remain elevated for years following treatment). However, the duration required for traits related to impulsivity to show meaningful change remains an open question. Thus, clinicians may need to incorporate measures of impulsivity into posttreatment assessment batteries (e.g., a 1-year follow-up). Further, establishing the extent to which current measures are sensitive enough to capture changes that may occur across durations common in treatment settings (e.g., 6-12 weeks) or designing new measures that are sensitive enough to capture meaningful change in this timeframe is needed.

In addition to assessment implications, interventions can indirectly address the influence of impulsivity on AUDs by targeting motivations for substance use. Recent work by Conrod et al. [55・•] focused on the long-term effects personality-targeted interventions, including targeting impulsivity and sensation seeking, have on numerous drinking domains (i.e., alcohol quantity frequency, alcohol problems, internal drinking motives). Intervention effects regarding alcohol use appear to be limited to the first 6 months following treatment, although significant reductions in problem drinking symptoms were shown across a 2-year follow-up period [55••]. Further, there was limited evidence that these interventions impacted drinking motives. Additionally, prior work from this dataset suggests the impact of these personalitytailored interventions varies by personality type (e.g., see Fig. 3 in [56]), which suggests targeting sensation seeking may be the most effective approach. Further, only one study from this group [57•] has shown personality-targeted interventions are more effective than placebo-control or personality-mismatched condition in reducing substance involvement. As discussed in Conrod et al. [55••], given that delivering personality-targeted interventions requires more effort than does delivering generic and often brief interventions, it will be essential for future studies to establish if personality-targeted interventions improve treatment outcomes compared with more general, nontailored treatment approaches. Moreover, in addition to personality-targeted 
behavioral and psychological interventions, pharmacological treatments targeting various constructs related to impulsivity may also be considered [58].

\section{Conclusions}

As is clear from this review, multiple, distinct traits associated with impulsivity are linked to a range of alcohol-related behaviors. Perhaps most interesting are the various ways that impulsivity-like traits may be associated with problematic alcohol involvement. Building on seminal studies, recent research has provided an increasingly refined understanding of how specific impulsivity constructs relate to distinct alcohol domains. Further, an emerging area of research has focused on the dynamic relations between impulsivity and alcohol outcomes, providing tantalizing clues regarding the functional relation among these constructs. Several research groups have began to focus on the utility of impulsivity-informed clinical efforts, and interventions that focus on traits associated with impulsivity may prove fruitful in improving interventions for AUDs.

Despite the progress made in recent work, there remain numerous high-priority areas for future research in this area (see [9] for more details). Most studies that have documented relations between impulsivity and alcohol involvement have relied on self-report questionnaires. Given the drawbacks to self-report questionnaires (e.g., potentially inaccurate insight [59]) and the modest correspondence between self-reports and informant-reports of personality [60], future research focused on linking impulsivity with alcohol use and related consequences may benefit from the use of multi-informant data. Relatedly, although a review of these measures and the relevant empirical findings is beyond the scope of this article, multimethod approaches to assessing impulsivity, such as using laboratory-based tasks thought to assess prepotent response inhibition [61], should be used to tap various aspects of impulsive functioning. However, a recent meta-analysis [62] suggests small correlations between self-report measures of impulsivity-related constructs and behavioral laboratory tasks, and thus researchers should be aware that these measures are most likely tapping different constructs that are broadly referred to as "impulsivity." Additionally, determining which measures of impulsivity best capture state versus trait variance would be helpful on a number of fronts, including informing clinical assessments that wish to track changes in impulsivity across treatment.

As noted by Littlefield et al. [39•], research that seeks to clarify alternative causal models involving impulsivity and alcohol use (e.g., does impulsivity lead to heavy drinking or does heavy drinking lead to increased impulsivity?) would require controlled experiments or a universally agreed on instrumental variable (see [41] for a detailed discussion of instrumental variables). Among other ways, this could be accomplished by examining the longitudinal impact of an alcohol intervention on the change in impulsivity or conversely the influence of an intervention designed to reduce impulsivity on changes in alcohol-related behaviors. Natural experiments, such as the impact of higher taxes on alcohol on both drinking rates and levels of impulsivity, could also be conducted.

Finally, given the theoretical pathways linking impulsivity and alcohol use described above are not mutually exclusive and most likely overlap, empirical models that integrate impulsivity, problematic alcohol involvement, and related constructs (e.g., drinking motives) within a developmental and genetic context are needed. Given phenotypes such as problematic alcohol involvement and personality characteristics such as impulsivity appear to be genetically complex [63], large, genetically informed prospective studies may be needed to develop replicable models that seek to integrate the various ways that various types of impulsivity relate to problematic alcohol involvement.

\section{Compliance with Ethics Guidelines}

Conflict of Interest Andrew K. Littlefield, Angela K. Stevens, and Kenneth J. Sher declare that they have no conflict of interest.

Human and Animal Rights and Informed Consent This article does not contain any studies with human or animal subjects performed by any of the authors.

\section{References}

Papers of particular interest, published recently, have been highlighted as:

- Of importance

•- Of major importance

1. Moeller FG, Barratt ES, Dougherty DM, et al. Psychiatric aspects of impulsivity. Am J Psychiatry. 2001;158:1783-93.

2. Evenden J. Impulsivity: a discussion of clinical and experimental findings. J Psychopharmocol. 1999;13:180-92.

3. Cyders MA, Smith GT, Spillane NS, et al. Integration of impulsivity and positive mood to predict risky behavior: development and validation of a measure of positive urgency. Psychol Assess. 2007;19:107-18.

4. Smith GT, McCarthy DM, Zapolski TCB. On the value of homogeneous constructs for construct validation, theory testing, and description of psychopathology. Psychol Assess. 2009;21:272-84.

5. Whiteside SP, Lynam DR. The five factor model and impulsivity: using a structural model of personality to understand impulsivity. Pers Individ Differ. 2001;30:669-89.

6. Coskunpinar A, Dir AL, Cyders MA. Multidimensionality in impulsivity and alcohol use: a meta-analysis using the UPPS model of impulsivity. Alcohol Clin Exp Res. 2013;37:1441-50.

7. Sher KJ, Trull TJ, Bartholow B, Vieth A. Personality and alcoholism: issues, methods, and etiological processes. In: Blane H, 
Leonard K, editors. Psychological theories of drinking and alcoholism. 2nd ed. New York: Plenum; 1999. p. 55-105.

8. Littlefield AK, Sher KJ. The multiple, distinct ways that personality contributes to alcohol use disorders. Soc Pers Psychol Compass. 2010;4:767-82.

9. Littlefield AK, Sher KJ. Personality and substance use disorders. In: Sher KJ, editor. Handbook of substance use and substance use disorders. New York: Oxford University Press; in press.

10. de Wit H. Impulsivity as a determinant and consequence of drug use: a review of underlying processes. Addict Biol. 2009;14:22-31.

11. Fernie G, Peeters M, Gullo MJ, et al. Multiple behavioural impulsivity tasks predict prospective alcohol involvement in adolescents. Addiction. 2013;108:1916-23.

12. Stautz K, Cooper A. Impulsivity-related personality traits and adolescent alcohol use: a meta-analytic review. Clin Psychol Rev. 2013;33:574-92. This is the first meta-analysis linking specific impulsivity facets to specific alcohol outcomes.

13. King KM, Fleming CB, Monahan KC, Catalano RF. Changes in self-control problems and attention problems during middle school predict alcohol, tobacco, and marijuana use during high school. Psychol Addict Behav. 2011;25:69-79.

14. King KM, Patock-Peckham JA, Dager AD, Thimm K, Gates JR. On the Mis-measurement of Impulsivity: Trait, Behavioral, and Neural Models in Alcohol Research Among Adolescents and Young Adults. Curr Addict Rep. doi: 10.1007/s40429-013-0005-4.

15. Cloninger CR. Neurogenetic adaptive mechanisms in alcoholism. Science. 1987;236:410-6

16. Sher KJ, Walitzer KS, Wood PK, Brent EE. Characteristics of children of alcoholics: putative risk factors, substance use and abuse, and psychopathology. J Abnorm Psychol. 1991;100:427-48.

17. Kirisci L, Vanyukov M, Tarter R. Detection of youth at high risk for substance use disorders: a longitudinal study. Psychol Addict Behav. 2005;19:243-52.

18. Slutske WS, Heath AC, Madden PAF, et al. Personality and the genetic risk for alcohol dependence. J Abnorm Psychol. 2002;111: 124-33.

19. Cloniger CR, Przybeck TR, Svrakic DM. The tridimensional personality questionnaire: U.S. normative data. Psychol Rep. 1999;69: 1047-57.

20. Eysenck SBG, Eysenck HJ, Barrett P. A revised version of the psychoticism scale. Pers Individ Differ. 1985;6:21-9.

21. Littlefield AK, Agrawal A, Ellingson J, et al. Does variance in drinking motives explain the genetic overlap between personality and alcohol use disorder symptoms? A twin study of young women. Alcohol Clin Exp Res. 2011;35:2242-50. This is the first study showing the genetic overlap between specific traits related to impulsivity, AUD symptoms, and drinking motives.

22. Tellegen A. Brief manual for the Multidimensional Personality Questionnaire. Minneapolis: University of Minnesota; 1982.

23. Barnes GE. Characteristics of the clinical alcoholic personality. J Stud Alcohol. 1980;41:894-910.

24. Littlefield AK, Sher KJ, Wood PK. Is 'maturing out' of problematic alcohol involvement related to personality change? J Abnorm Psychol. 2009;118:360-74.

25. Sher KJ, Wood M, Crews T, Vandiver TA. The Tridimensional Personality Questionnaire: reliability and validity studies and derivation of a short form. Psychol Assess. 1995;7:195-208.

26. Eysenck HJ, Eysenck SBG. Manual of the Eysenck Personality Questionnaire. Educational and Industrial Testing Services: San Diego; 1968

27. Littlefield AK, Sher KJ, Wood PK. Do changes in drinking motives mediate the relation between personality change and the "maturing out" of alcohol problems? J Abnorm Psychol. 2010;119:93-105.

28. Hicks BM, Durbin CE, Blonigen DM, et al. Relationship between personality change and the onset and course of alcohol dependence in young adulthood. Addiction. 2011;107:540-8.
29. Quinn PD, Harden KP. Differential changes in impulsivity and sensation seeking and the escalation of substance use from adolescence to early adulthood. Dev Psychol. 2013;25:223-39.

30. Harden KP, Tucker-Drob EM. Individual differences in the development of sensation seeking and impulsivity during adolescence: further evidence for a dual systems model. Dev Psychol. 2011;47: 739-46.

31. Ellingson JM, Verges A, Littlefield AK, et al. Are bottom-up and top-down processes in dual-process models of personality genetically distinct? Behav Genet. in press.

32. Steinberg L, Albert D, Cauffman E, et al. Age differences in sensation seeking and impulsivity as indexed by behavior and self-report: evidence for a dual systems model. Dev Psychol. 2008;44:1764-78

33. Littlefield AK, Sher KJ, Wood PK. A personality-based description of maturing out of alcohol problems: extension with a five-factor model and robustness to modeling challenges. Addict Behav. 2010;35:948-54.

34. Wood PK, Jackson KM. Escaping the snare of chronological growth and launching a free curve alternative: general deviance as latent growth model. Dev Psychopathol. 2013;25:739-54.

35. Littlefield AK, Sher KJ, Steinley D. Developmental trajectories of impulsivity and their association with alcohol use and related outcomes during emerging and young adulthood. Alcohol Clin Exp Res. 2010;34:1409-16.

36. Quinn PD, Stappenbeck CA, Fromme K. Collegiate heavy drinking prospectively predicts change in sensation seeking and impulsivity. J Abnorm Psychol. 2011;120:43-556. This is the first study to examine causal transactional pathways between alcohol involvement and traits related to impulsivity.

37. McArdle JJ. Latent variable modeling of differences and changes with longitudinal data. Annu Rev Psychol. 2009;60:577-605.

38. Zuckerman M, Kuhlman DM, Joireman J, et al. A comparison of three structural models for personality: the Big Three, the Big Five, and the Alternative Five. J Pers Soc Psychol. 1993;65:757-68.

39. Littlefield AK, Vergés A, Wood PK, Sher KJ. Transactional models between personality and alcohol involvement: a further examination. J Abnorm Psychol. 2012;121:778-83. This is the first study to examine the robustness of causal transactions pathways between alcohol involvement and traits related to impulsivity.

40. Tomarken AJ, Waller NG. Potential problems with "well fitting" models. J Abnorm Psychol. 2003;112:578-98.

41. Gennetian LA, Magnuson K, Morris PA. From statistical associations to causation: what developmentalists can learn from instrumental variable techniques coupled with experimental data. Dev Psychol. 2008;44:381-94.

42. Cooper ML. Motivations for alcohol use among adolescents: development and validation of a four-factor model. Psychol Assess. 1994;6:117-28.

43. Cox WM, Klinger E. A motivational model of alcohol use. J Abnorm Psychol. 1998;97:168-80.

44. Cox WM, Klinger E. Incentive motivation, affective change and alcohol use: a model. In: Cox WM, editor. Why people drink: parameters of alcohol as a reinforcer. New York: Garden; 1990. p. 291-314.

45. Cooper ML, Frone MR, Russell M, Mudar P. Drinking to regulate positive and negative emotions: a motivational model of alcohol use. J Pers Soc Psychol. 1995;69:990-1005.

46. Kuntsche EN, von Fischer M, Gmel G. Personality factors and alcohol use: a mediator analysis of drinking motives. Pers Individ Differ. 2008:45:796-800.

47. Stewart SH, Devine H. Relations between personality and drinking motives in young adults. Pers Individ Differ. 2000;29:495-511.

48. Kuntsche E, Knibbe R, Gmel G, Engels R. Who drinks and why? A review of socio-demographic, personality, and contextual issues behind the drinking motives in young people. Psychol Addict Behav. 2006;31:1844-57. 
49. Kuntsche EN, Knibbe R, Gmel G, Engels R. Why do young people drink? A review of drinking motives. Clin Psychol Rev. 2005;25: 841-61.

50. Stojek M, Fischer S. Impulsivity and motivations to consume alcohol: a prospective study on risk dependence in young adult women. Alcohol Clin Exp Res. 2013;37:292-9.

51. Cooper ML, Agocha VB, Sheldon MS. A motivational perspective on risky behaviors: the role of personality and affect regulatory processes. J Pers. 2000;68:1059-88.

52. Hussong AM, Galloway CA, Feagans LA. Coping motives as a moderator of daily mood-drinking covariation. J Stud Alcohol Drugs. 2005;66:344-53.

53. Littlefield AK, Talley AE, Jackson KM. Coping motives, negative moods, and time-to-drink: exploring alternative analytic models of coping motives as a moderator of daily mood-drinking covariation. Addict Behav. 2012;37:1371-6.

54. Piasecki TM, Cooper ML, Wood PK, et al. Dispositional drinking motives: associations with appraised alcohol effects and alcohol consumption in an ecological momentary assessment investigation. Psychol Assess. in press.

55.• Conrod PJ, Castellanos-Ryan N, Mackie C. Long-term effects of a personality-targeted intervention to reduce alcohol use in adolescents. J Consult Clin Psychol. 2011;79:296-306. This is the first study to show the long-term effects of personality-targeted interventions on alcohol outcomes.

56. Conrod PJ, Castellanos N, Mackie C. Personality-targeted interventions delay the growth of adolescent drinking and binge drinking. J Child Psychol Psychiatry. 2008;49:18190.

57. Bickel WK, Yi R, Landes RD, et al. Remember the future: working memory training decreases temporal discounting among stimulant addicts. Biol Psychiatry. 2011;69:260-5. This is the first study to show working memory training decreases delay discounting in a clinical setting.

58. Leeman RF, Bogart D, Fucito LM, Boettiger, CA. "Killing two birds with one stone": alcohol use reduction interventions with potential efficacy in enhancing self-control. Curr Addict Rep. in press.

59. Klonsky ED, Oltmanns TF, Turkheimer E. Informant reports of personality disorder: Relation to self-reports and future research directions. Clin Psychol. 2002;9:300-11.

60. Oltmanns TF, Turkheimer E, Strauss ME. Peer assessment of personality traits and pathology. Assessment. 1998;5:53-65.

61. Marczinski CA, Fillmore MT. Preresponse cues reduce the impairing effects of alcohol on the execution and suppression of responses. Exp Clin Psychopharmacol. 2003;11:110-7.

62. Cyders MA, Coskunpinar A. Measurement of constructs using selfreport and behavioral lab tasks: is there overlap in nomothetic span and construct representation for impulsivity? Clin Psychol Rev. 2011;31:965-82.

63. McCrae RR, Scally M, Terracciano A, et al. An alternative to the search for single polymorphisms: toward molecular personality scales for the five-factor model. J Pers Soc Psychol. 2010;99:1014-24.

64. Cyders MA, Smith GT. Emotion-based dispositions to rash action: positive and negative urgency. Psychol Bull. 2008;134:807-28. 